Original research article

\title{
Effect of Intravenous Dexamethasone on Spinal Anaesthesia With Bupivacaine Plus Fentanyl in Patients Undergoing Vaginal Hysterectomy
}

\author{
Sourabh Roy ${ }^{1}$, Soma Datta ${ }^{2}$ \\ ${ }^{1}$ Associate Professor, Department of Anesthesiology, KPC Medical College, Kolkata, India 2 Assistant \\ Professor, Department of obstetrics \& gynecology, JIMS, Kolkata
}

\begin{abstract}
Background: Many adjuvant drugs have been used to enhance postoperative neuraxial opioid analgesia while reducing the adverse effects.

Methods: We randomized 50 patients undergoing various lower abdominal operations into 2 equal groups to receive either $2 \mathrm{~mL}$ saline or $0.1 \mathrm{mg} / \mathrm{kg}$ dexamethasone IV before the administration of intrathecal anesthesia (15 $\mathrm{mg}$ bupivacaine heavy and fentanyl $25 \mathrm{mcg}$ ). After surgery, pain was assessed with the help of a 100mm visual analogue scale where 0 means no pain at all and 100 signifies the worst pain experience possible. The rescue analgesic was administered when the pain score exceeded 40. After administration of rescue analgesic the patients were asked to score their pain at $6,12,18$, and $24 \mathrm{~h}$. The presence of postoperative nausea and vomiting (PONV), pruritus and respiratory depression were recorded.

Results: The total dose of diclofenac, visual analog scale pain score, and the incidence of PONV were significantly lower in the dexamethasone group than in control.

Conclusions: Administration of IV dexamethasone prior to intrathecal fentanyl injection enhances analgesia and reduces $P O N V$.
\end{abstract}

\section{Introduction}

Spinal anaesthesia is the technique of choice for lower abdominal operations including vaginal hysterectomy. Bupivacaine is the most common spinally used anaesthetic.However to address the problem of limited duration of action and to improve the quality of analgesia both intra-operatively and post-operatively, intrathecal opiates like morphine and more recently fentanyl have been given in addition to bupivacaine(1-3). However the risks of delayed respiratory depression, nausea, vomiting, pruritus, urinary retention are inherent to the use of IT opioids $(4,5)$. Since both analgesia and adverse effects are dose-dependent, techniques that potentiate the analgesic effects of intrathecal fentanyl, allowing for a reduction in its subarachnoid dosage without increasing its side effects, is of interest. Dexamethasone, a corticosteroid with strong anti-inflammatory effects, provides postoperative analgesia (6-8), prevents nausea and vomiting in patients undergoing chemotherapy $(9-12)$, and reduces postoperative nausea and vomiting (PONV) (8, 13-16).However, prophylaxis with dexamethasone in intrathecal fentanyl-related analgesia, nausea, and vomiting has not been reported. The aim of the present study was to determine whether a combination of IV dexamethasone and subarachnoid fentanyl would enhance the analgesic effect of subarachnoid fentanyl and reduce its adverse effects of nausea and vomiting under spinal bupivacaine anesthesia.

\section{Methods}

We studied 80 ASA I and II patients (American Society of Anesthesiologists grading system ASA I _ a normal healthy individual, ASA II _ a patient with mild systemic disease) undergoing vaginal hysterectomy under spinal anaesthesia. Informed consent was obtained from all patients and the study was approved by the Hospital Ethics Committee. The exclusion criteria included known allergy or contraindication to any of the test drugs or spinal anesthesia (e.g., coagulation defects, infection at the puncture site, or preexisting neurological deficits in the lower extremities). Patients were randomized by the sealed envelope method (on the basis of a block-randomized computer-generated list), and the randomization code was kept separate and not known to any of the investigators until the study was finished. The drug/placebo solution was drawn into a syringe by a nurse not participating in the study and was delivered to the investigator (TB) who was outside the medicine room and unaware of the content. The saline and dexamethasone solutions appeared transparent and completely identical at the time syringes were given to the investigator. Thus, the patient, the anesthesiologist, the surgeon, and the study observer were all blinded with respect to the study group. The study drug was administered to the patient within 5 minutes after drawn into the syringes. 
None of the patients received any premedication.They were randomly assigned into either the dexamethasone group (Group A) or the placebo group (Group B). The patients in Group B received IV $2 \mathrm{~mL}$ saline and those in Group A received IV $0.1 \mathrm{mg} / \mathrm{kg}$ dexamethasone just before spinal anesthesia. After the administration of IV medication, spinal puncture was performed at the L2-3 or L3-4 interspace with a 22- gauge introducer needle and 27-gauge Sprotte needle by using a midline approach with the patient in the modified Oxford position. The spinal drugs were given over $30 \mathrm{~s}$. All the patients in both the groups received 10mg bupivacaine and fentanyl $12.5 \mathrm{mcg}$ via the subarachnoid route. Immediately after the administration of the spinal drugs, the patients were placed horizontally in the supine position and were maintained in the same position throughout surgery. All patients were given $15 \mathrm{~mL} / \mathrm{kg}$ of compound Ringer's lactate solution as a circulatory preload followed by infusion at $6-10 \mathrm{~mL} / \mathrm{kg} / \mathrm{hr}$ through a $16 \mathrm{G}$ cannula. All patients were routinely given supplemental oxygen via a ventimask at the rate of $4 \mathrm{~L} / \mathrm{min}$. The level of sensory blockade to cold was assessed with a pin prick and cold touch method performed in the mid-clavicular line at an interval of 2 min for $20 \mathrm{mins} \&$ then every $10 \mathrm{mins}$. The Onset, Duration, Highest level of sensory block \& time of regression to the L1 dermatome were noted. The patients were monitored continuously with ECG, Spo2, heart rate, non invasive blood pressure, and respiratory rate. The blood pressure was recorded every 2 minute during the procedure and every 5 mins thereafter for 120 minutes. Any fall in blood pressure greater than $20 \%$ decrease in systolic blood pressure or an absolute systolic arterial pressure less than $100 \mathrm{mmHg}$ was considered as hypotension and treated with boluses of mephentermine and fluids where appropriate. All episodes of hypotension, nausea and vomiting, shivering, somnolence, respiratory depression, inadequate analgesia and pruritus were recorded. Any treatment given for the side-effects was noted. The duration of surgery was also recorded. At 120 mins after the block was given, the patients were assessed for their degree of somnolence using the Campbell score (17)

(1 -wide awake; 2 - sedated but easily arousable; 3 - drowsy and difficult to arouse, and 4 - unarousable). Residual motor blockade was assessed using the Bromage scale (18).

( 0 - unable to move feet or knees, 1 - moves feet only, 2 -moves feet and knees, and 3 - full range of movements).

The patients were asked to assess the quality of the anaesthesia on a four-point modified Belzarena scale (19) (1 - unable to tolerate pain; 2 - able to tolerate discomfort with additional analgesia; 3 - some discomfort but no additional analgesics required, and 4 - completely satisfied).Pain was assessed with the help of a $100 \mathrm{~mm}$ visual analogue scale where 0 means no pain at all and 100 signifies the worst pain experience possible (20). This assessment was carried out at intervals of 6 hours for the first 24 hours. The rescue analgesic in the form of inj. Diclofenac sodium $75 \mathrm{mg}$ was administered on patient request. The incidences of nausea, vomiting and pruritus were evaluated with the help of a "yes" or "no" survey. Throughout the first postoperative day, the patients were interviewed to check for headache, backache, nausea and vomiting and pruritus. The presence of urinary retention was not assessed as our patients are routinely catheterised for 24 hours postoperatively. The duration of absolute analgesia and Effective analgesia, defined as the time to administer the first dose of postoperative analgesic, was recorded.

Sample size calculation was based on added total VAS scores of overall pain during first day from 35 consecutive patients undergoing vaginal hysterectomy receiving a similar anesthetic and analgesic treatment as placebo patients in the present study. With a power to detect a minimal relevant difference (MIREDIF) between surgical groups of 50\% and a type 1 and 2 error of 0.05 and 0.20 , respectively, 39 patients in each group would be adequate. We included $2 \times 40$ patients in the study. Parametric data were analyzed with unpaired $t$-test; the incidence of adverse effects was analyzed with Fisher's exact test. The VAS data were analyzed with the MannWhitney $U$-test A value of $P<0.05$ was considered statistically significant. Data were expressed as mean \pm S.D. of the mean.

\section{Results}

There were no significant differences in patient age, weight, height, inj to delivery interval or duration of surgery between the three groups ( $\underline{\text { Table I })}$.

Demographic profile of both the groups:

\begin{tabular}{|l|l|l|}
\hline Variables & $\begin{array}{l}\text { Gr A } \\
(\mathrm{n}=40)\end{array}$ & $\begin{array}{l}\text { Gr B } \\
(\mathrm{n}=40)\end{array}$ \\
\hline Age $(\mathrm{yr})$ & $46.2 \pm 4.1$ & $45.6 \pm 3.8$ \\
\hline Wt $(\mathrm{Kg})$ & $50.5 \pm 6.2$ & $52.4 \pm 4.1$ \\
\hline Height (inch) & $63.6 \pm 1.2$ & $62.3 \pm 1.3$ \\
\hline Surgical Time (min) & $100.2 \pm 5.2$ & $104.1 \pm 6.2$ \\
\hline
\end{tabular}


There was no significant difference in onset and the highest level of sensory blockade (Table II).

\section{Characteristics of the sensory block}

\begin{tabular}{|l|l|l|}
\hline Variables & $\begin{array}{l}\text { Gr A } \\
(\mathrm{n}=40)\end{array}$ & $\begin{array}{l}\text { Gr B } \\
(\mathrm{n}=40)\end{array}$ \\
\hline Highest sensory level & $\mathrm{T} 7(\mathrm{~T} 6-\mathrm{T} 8)$ & $\mathrm{T} 7$ (T6- T8) \\
\hline $\begin{array}{l}\text { Time to reach highest Sensory Level } \\
\text { (min) }\end{array}$ & $7.3 \pm 1.1$ & $8.2 \pm 2.2$ \\
\hline $\begin{array}{l}\text { Time for Sensory regression to L1 } \\
\text { from highest Sensory level (min) }\end{array}$ & $128.5 \pm 14.21$ & $127.7 \pm 8.4$ \\
\hline
\end{tabular}

There were no significant differences in between the two groups with regards to their onset and duration of motor block (Table III).

\section{Characteristics of motor block}

\begin{tabular}{|l|l|l|}
\hline Variables & $\begin{array}{l}\text { Gr A } \\
(\mathrm{n}=40)\end{array}$ & $\begin{array}{l}\text { Gr B } \\
(\mathrm{n}=40)\end{array}$ \\
\hline $\begin{array}{l}\text { Onset of Grade III motor block } \\
(\mathrm{min})\end{array}$ & $5.1 \pm 1.1$ & $5.2 \pm 1.2$ \\
\hline $\begin{array}{l}\text { Duration of Grade I motor block } \\
(\mathrm{min})\end{array}$ & $122.3 \pm 7.2$ & $125.8 \pm 8.1$ \\
\hline
\end{tabular}

Twenty-four Hour Visual analogue Score (VAS) assessment, VAS pain Score at 6-hr intervals (Table IV)

\begin{tabular}{|l|l|l|}
\hline $\begin{array}{l}\text { VAS pain scores }(\mathrm{mm}) \\
\text { Mean } \pm \text { SD }\end{array}$ & $\begin{array}{l}\text { Gr A } \\
(\mathrm{n}=40)\end{array}$ & $\begin{array}{l}\text { Gr B } \\
(\mathrm{n}=40)\end{array}$ \\
\hline $6 \mathrm{hr}$ & $00 \pm 10.3$ & $50.04 \pm 12.0 *$ \\
\hline $12 \mathrm{hr}$ & $17.00 \pm 12.2$ & $45.8 \pm 16.1 *$ \\
\hline $18 \mathrm{hr}$ & $13.3 \pm 1.08$ & $43.8 \pm 11.19 *$ \\
\hline $24 \mathrm{hr}$ & $12.3 \pm 13.8$ & $36.3 \pm 10.8 *$ \\
\hline $\mathrm{p}<0.05$ &
\end{tabular}

Total dose of diclofenac, Nausea \& Vomiting, Respiratory depression\& Pruritus numbers (Table V)

\begin{tabular}{|l|l|l|}
\hline Variables & $\begin{array}{l}\text { Gr A } \\
(\mathrm{n}=40)\end{array}$ & $\begin{array}{l}\mathrm{Gr} \mathrm{B} \\
(\mathrm{n}=40)\end{array}$ \\
\hline $\begin{array}{l}\text { Total dose of diclofenac (mg) } \\
\text { mean (range) (number) }\end{array}$ & $7.5(0-75)(3)$ & $31.5(0-225)(10) *$ \\
\hline 24-hr nausea number (\%) & $2(12.5 \%)$ & $9(54.5 \%) *$ \\
\hline 24-hr vomiting number (\%) & $2(12.5 \%)$ & $8(48.5 \%)^{*}$ \\
\hline Respiratory depression number & 0 & 0 \\
\hline Pruritus (number) & 1 & 2 \\
\hline
\end{tabular}

$* \mathrm{p}<0.05$

Side-effects in percentage (Table VI)

\begin{tabular}{|l|l|l|l|l|l|l|}
\hline & hypoten. & brady. & R. depr & Shivering & Emesis & Pruritus \\
\hline GR A & 18 & 12 & 0 & 12 & 12 & 6 \\
\hline GR B & 18 & 6 & 0 & 30 & 49 & 12 \\
\hline
\end{tabular}

There was a significant decrease in the incidence of pruritus with the addition of intravenous dexamethasone. These patients complained of mild itching affecting mainly the nose and face. Of these patients, only 2 required treatment for the itching while others resolved spontaneously. The incidences of hypotension were similar in both the groups. These episodes were treated with boluses of mephentermine and fluid loading. Nausea was reported in $4 \%$ (2/50) in the fentanyl group and $24 \%(12 / 50)$ in the bupivacaine alone group. There was a significant difference between the groups. There were no significant differences in the degree of somnolence or motor blockade 120 mins after intrathecal injection of the study solutions. There was a significant difference in the patients' assessment of intra-operative anaesthesia at 120 mins. The satisfaction scores were much higher in the study group. (Table VII)

\begin{tabular}{|l|l|}
\hline & BELZARENA SCORE \\
\hline Gr A & $96 \%$ \\
\hline Gr B & $64 \%$ \\
\hline
\end{tabular}

\section{Discussion}

Previous studies have demonstrated the analgesic and antiemetic effects of i.v. corticosteroids $(6-16)$. In our study, time to first demand, number of administrations of IM diclofenac,VAS pain score at four-hour intervals and 24 hours, and the incidence of nausea and vomiting were significantly reduced between the two 
groups while the duration of absolute analgesia was prolonged. This result is in synchrony with several previous studies $(6-16)$.One study has demonstrated that dexamethasone administered orally could decrease wound pain after tooth extraction (6) .Similarly another study has shown a reduction in pain, fatigue, nausea and vomiting, and duration of convalescence in patients undergoing uncomplicated Laparoscopic Cholecystectomy and receiving intravenous dexamethasone when compared to placebo, and recommends preoperative dexamethasone $(8 \mathrm{mg}$ ) for routine use (21). Movafegh et al have also shown a prolongation of analgesia after intrathecal meperidine (22).However at least one study fails to demonstrate any such effect of dexamethasone after inguinal herniorrhaphy (23). The mechanism of analgesic action of dexamethasone is not conclusively proved. Acute noxious stimulation of peripheral tissues leads to sensitization of dorsal horn neurons of the spinal cord by the release of excitatory amino acids such as glutamate and aspartate. These amino acids activate N-methyl-Daspartate receptors resulting in calcium ion influx (24). The increased intracellular calcium leads to activation of phospholipase A2, the rate-limiting enzyme in prostaglandin synthesis, which converts membrane phospholipids to arachidonic acid. Simultaneously, there is up-regulation of the expression of cyclo-oxygenase- 2 in the spinal cord, leading to prostaglandin E2 synthesis and a resultant hyperalgesic state(25,26 ).Corticosteroids are capable of reducing prostaglandin synthesis by inhibiting phospholipase A2 through the production of calciumdependent phospholipid binding proteins called annexins( 27), and by the inhibition of cyclo-oxygenase-2 during inflammation.(28).

Dexamethasone IV is an effective antiemetic for chemotherapy-associated emesis (9-12). Dexamethasone also reduced PONV in patients undergoing tonsillectomy $(13,15)$ and major gynecologic surgery $(8,16)$. Because dexamethasone reduces chemotherapy associated emesis and PONV, it seems reasonable that it may also be effective in the prevention of IT fentanyl-associated emesis. The antiemetic mechanism of corticosteroids is unknown. Dexamethasone may inhibit the synthesis of prostaglandin, which is related to the triggering of emesis (10). Previous studies suggested that decreased serotonin release in the central nervous system and changes in the permeability of the blood cerebrospinal fluid barrier to serum proteins (14) may also play a role in the antiemetic effects of corticosteroids. The complex act of vomiting is controlled by the emetic center, which can be affected by stimuli from several areas, including the chemoreceptor trigger zone (CTZ) in the area postrema (17). The CTZ is rich in dopamine, opioid, serotonin, histamine, and muscarinic cholinergic receptors; these may play an important role in the transmission of impulses to the emetic center (17) However, no currently available drug will antagonize all receptor sites involved in the emetic response. Hursti et al. (29) demonstrated an antiemetic effect of exogenous corticosteroid only in patients with low endogenous corticosteroids. In addition, dexamethasone $8 \mathrm{mg}$ alone did not reduce PONV (30), although the reported dose of dexamethasone for prevention of PONV ranges from $0.15 \mathrm{mg} / \mathrm{kg}$, up to a maximum of $10 \mathrm{mg} \mathrm{IV,} 8 \mathrm{mg}$ orally $(6,16)$. The possible adverse effects associated with the administration of corticosteroids, such as retardation of wound healing, increased susceptibility to infection, and gastrointestinal hemorrhage, were not found in this study because no prolonged hospital stay occurred because of wound infection or delayed healing and no hematemesis or melaena happened in the patients. Previous studies $(8,13,15,30)$ also have demonstrated that short-term (24 hours) use of corticosteroids was safe. However, the precise dose of corticosteroid or duration of therapy with a corticosteroid that may cause corticosteroid-related adverse effects is unclear, particularly in patients at risk for such adverse effects. It is also unclear whether a single dose of dexamethasone can suppress adrenal function in patients during surgery. The levels of dizziness and anxiety observed in this study were relatively mild, and there was no difference in the incidence between groups. Pruritus and respiratory depression were not observed in any of the patients. In conclusion, we found that prophylactic administration of IV dexamethasone $0.1 \mathrm{mg} / \mathrm{kg}$ did enhance the analgesia and reduced the incidence of emesis in patients receiving spinal anesthesia with bupivacaine plus fentanyl during vaginal hysterectomy.

\section{References}

[1]. Singh H, Yang J, Thornton K, Giesecke AH. Intrathecal fentanyl prolongs sensory bupivacaine spinal block. Can J Anaesth 1995; 42:987-91.

[2]. Gran JA. Sufentanil: Clinical use as postoperative analgesia - epidural/intrathecal route. J Pain Symptom Manage 1992 7; 5:271-86

[3]. Abboud TK, Dror A, Mosaad P, Zhu J, Mantilla M, Swart P, et al. Mini dose intrathecal morphine for the relief of post-cesarean section pain: safety, efficacy and ventilatory responses to carbon dioxide. Anesth Analg 1988; 67:137-43.

[4]. Palmer CM. Early respiratory depression following intrathecal fentanyl-morphine combination. Anesthesiology 1991; 74:1153-5.

[5]. Hays RL, Palmer CM. Respiratory depression after intrathecal sufentanil during labor. Anesthesiology 1994; 81:511-2.

[6]. Baxendale BR, Vater M, Lavery KM. Dexamethasone reduces pain and swelling following extraction of third molar teeth. Anaesthesia 1993;48:961- 4 .

[7]. Aasboe V, Raeder JC, Groegaard B. Betamethasone reduces postoperative pain and nausea after ambulatory surgery. Anesth Analg 1998;87:319-23.

[8]. Fujii Y, Tanaka H, Toyooka $\mathrm{H}$. The effects of dexamethasone on antiemetics in female patients undergoing gynecologic surgery. Anesth Analg 1997;85:913-7.

[9]. Aapro MS, Alberts DS. Dexamethasone as an antiemetic in patients treated with cisplatin [letter]. N Engl J Med 1981;305:520

[10]. Aapro MS, Plezia PM, Alberts DS, et al. Double-blind cross-over study of the antiemetic efficacy of high-dose dexamethasone versus high-dose metoclopramide. J Clin Oncol 1984;2:466 -7.

[11]. Tavorath R, Hesketh PJ. Drug treatment of chemotherapyinduced delayed emesis. Drugs 1996;52:639-48. 
[12]. Jones AL, Hill AS, Soukop M, et al. Comparison of dexamethasone and ondansetron in the prophylaxis of emesis induced by moderately emetogenic chemotherapy. Lancet 1991;338: 483-7.

[13]. Splinter WM, Rhine EJ. Low-dose ondansetron with dexamethasone more effectively decreases vomiting after strabismus surgery in children than does high-dose ondansetron. Anesthesiology 1998;88:72-5.

[14]. Livrea P, Trojano M, Simone I. Acute changes in blood CSF barrier permselectivity to serum proteins after intrathecal methotrexate and CNS irritation. J Neurol 1985;231:336-9.

[15]. Pappas ALS, Sukhani R, Hotaling AJ, et al. The effect of preoperative dexamethasone on the immediate and delayed postoperative morbidity in children undergoing adenotonsillectomy. Anesth Analg 1998;87:57-61.

[16]. Liu K, Hsu CC, Chia YY. The effective dose of dexamethasone for antiemesis after major gynecological surgery. Anesth Analg 1999;89:1316-8.

[17]. Campbell DC, Camann WR, Datta S. The addition of bupivacaine to intrathecal sufentanil for labor analgesia. Anesth Analg 1995; $81: 305-9$.

[18]. Bromage PR. A comparison of the hydrochloride and carbon dioxide salts of lidocaine and prilocaine in epidural analgesia. Acta Anaesthesiol Scand 1965; 16:55-69.

[19]. Belzarena SD. Clinical effects of intrathecally administered fentanyl in patients undergoing cesarean section. Anesth Analg 1992; 74:653-7.

[20]. Duggleby W \& Lander J. J of Pain and Symptom Management, 1994; 9(1):19-27

[21]. Thue Bisgaard, Birthe Klarskov, Henrik Kehlet, Jacob Rosenberg. Preoperative Dexamethasone Improves Surgical Outcome After Laparoscopic Cholecystectomy A Randomized Double-Blind Placebo-Controlled Trial Ann Surg. 2003 November; 238(5): $651-660$.

[22]. Ali Movafegh, Ahmad Reza Soroush, Ali Navi Mustafa Sadeghi, Fatimah Esfehani, Niloufar Akbarian-Tefaghi The Effect of Intravenous Administration of Dexamethasone on Postoperative Pain, Nausea, and Vomiting After Intrathecal Injection of Meperidine Anesth Analg 2007;104:987-989

[23]. Ping-Heng Tan, Kang Liu, MD, Chih-Hsien Peng, Ling-Cheng Yang, Chung-Ren Lin, Cheng-Yuan Lu. The Effect of Dexamethasone on Postoperative Pain and Emesis After Intrathecal Neostigmine Anesth Analg 2001;92:228-32

[24]. Siji Thomas, Suhara Beev. Epidural dexamethasone reduces postoperative pain and analgesic requirements Can J Anesth 2006 / 53: 9/pp 899-905

[25]. Abram SE, Marsala M, Yaksh TL. Analgesic and neurotoxic effects of intrathecal corticosteroids in rats. Anesthesiology 1994; 81: $1198-205$.

[26]. Ebersberger A, Grubb BD, Willingale HL, Gardiner NJ, Nebe J, Schaible HG. The intraspinal release of prostaglandin E2 in a model of acute arthritis is accompanied by an up-regulation of cyclo-oxygenase-2 in the spinal cord. Neuroscience 1999; 93 : 77581.

[27]. Yao XL, Cowan MJ, Gladwin MT, Lawrence MM, Angus CW, Shelhamer JH. Dexamethasone alters arachidonate release from human epithelial cells by induction of p11 protein synthesis and inhibition of phospholipase A2 activity. J Biol Chem 1999; 274 : 17202-8.

[28]. Lubenow TR, Ivankovich AD, McCarthy RJ. Management of acute postoperative pain. In: Barash PG, Cullen BF, Stoelting RK (Eds). Clinical Anesthesia, 4th ed. Philadelphia: Lippincott Williams \& Wilkins Inc; 2001: 1403-34.

[29]. Hursti TJ, Fredrikson M, Steineck G, et al. Endogenous cortisol exerts antiemetic effect similar to that of exogenous corticosteroids. Br J Cancer 1993;68:112-4.

[30]. Fujii Y, Tanaka H, Toyooka H. Granisetron-dexamethasone combination reduces postoperative nausea and vomiting. Can J Anaesth 1995;42:387-90.

Corresponding author :Dr Sourabh Roy, email :drsourabhroy@gmail.com 